Bangladesh J Med Microbiol 2008; 02 (01): 22-27

Bangladesh Society of Medical Microbiologists

Original Article

\title{
Aerobic Bacterial Pattern in Puerperal Sepsis
}

Salma Ahmed ${ }^{1}$, Md. Akram Hossain ${ }^{1}$, AKM Shamsuzzaman¹, Asma Azad Sumona1 ${ }^{1}$ Zahura Bagum², Nahid Akter Zahan ${ }^{1}$, AKM Musa ${ }^{1}$, Md. Chand Mahmud ${ }^{1}$, Kamrun Nahar ${ }^{3}$, Sheikh Shorif Uddin Ahmed ${ }^{4}$, SA Nurul Huda ${ }^{5}$ Mesbah Uddin Ahmed 6

${ }^{1}$ Department of Microbiology, Mymensingh Medical College, Mymensingh; 2 Department of Microbiology, Community Based Medical College, Mymensigh; ' ${ }^{3}$ Department of Obstetrics and Gynaecology, Mymensigh Medical College Hospital, Mymensigh; ${ }^{4}$ Bangladesh Agricultural University, Mymensigh; 5Department of Pharmacology, Mymensigh Medical College, Mymensigh; ${ }^{6}$ Department of Microbiology, Enam Medical College, Savar, Dhaka

\begin{abstract}
Puerperal sepsis is an important cause of maternal morbidity and mortality in developing countries. This study was undertaken to isolate and identify the Aerobic bacterial agents of Puerperal sepsis among the patients admitted in Mymensingh Medical College Hospital during the period from July, 2006 to June, 2007. Endocervical swabs/ secretions were collected from 50 cases of Puerperal sepsis and were cultured aerobically. Out of 50 samples, 42 (84\%) yielded growth in cultures. Among 42 culture positive cases, 20 (40\%) were Aerobic organisms and 22 (44\%) were mixed, i.e., Aerobic and Anaerobic bacteria. The isolated Aerobic organisms were Staphylococcus aureus (26, 61.90\%), Escherichia coli (6, 14.28\%), Staphylococcus epidermidis (5, 11.90\%), Streptococcus pyogenes (3, 7.14\%) and Enterococcus faecalis (2, 4.76\%). The organisms were identified by standard biochemical tests. All isolates of $S$. aureus and $\boldsymbol{S}$. epidermidis were sensitive to Cephalexin and Vancomycin. Similarly all the strains of $\boldsymbol{E}$. coli were sensitive to Gentamicin, Amikacin, Ciprofloxacin and Cephalexin. All the strains of $S$. pyogenes were sensitive to Amoxicillin and all the isolates of Enterococcus were sensitive to Amoxicillin and Cephalexin.
\end{abstract}

Key words: Pueperal sepsis, Aerobic organisms, Anaerobic organisms, Maternal morbidity and mortality

\section{Introduction}

Puerperal sepsis is an infection of the genital tract at the time interval between rupture of amniotic membrane and the $42 \mathrm{nd}$ day following delivery or abortion. Two or more of the following manifestations must be present to define the condition. The manifestations are: pelvic pain, fever of $38.45^{\circ} \mathrm{C}$ or more, abnormal vaginal discharge with foul odour and delayed reduction of uterine size. ${ }^{1}$ The recorded incidence of maternal sepsis was 1.7, 0.22, 0.07, 0.15 and 4.5 per 100 live births in Nigeria, Niger, South Africa, USA and

Correspondence:

Dr. Salma Ahmed

Lecturer, Department of Microbiology

Mymensingh Medical College, Mymensingh
Bangladesh respectively.2,3,4 One study from Nigeria and another from Senegal reported rate of post-partum genital sepsis as $14.8 \%$ and $8.7 \%$ among women who delivered at home compared to $7.9 \%$ and $1.9 \%$ in those who delivered in hospitals with proper healthcare facilities respectively.5,6 Over 3.5 million women in Bangladesh become pregnant every year and not less than 20,000 of them die while giving birth to their babies. In Mymensingh Medical College Hospital $(\mathrm{MMCH})$ during the year 1984-88, it was found that $17 \%$ maternal death had been caused by Puerperal sepsis. ${ }^{7}$ Another study in Dhaka Medical College showed 20.3\% maternal death due to Puerperal sepsis. ${ }^{8}$ One of the predisposing conditions usually leading to the Puerperal sepsis is the home delivery in unhygienic conditions and should be included at the top of the list. Other factors include low socioeconomic condition, anaemia, parity as primigravida, prolonged period 
of delivery after rupture of the amniotic membrane, frequent per vaginal examinations and prolonged labour. 9

The causative organisms of Puerperal sepsis are Streptococcus pyogenes and other Beta-haemolytic Streptococci, Enterococcus faecalis, Anaerobic cocci, Clostridium perfringens, Bacteroides species, Proteus species, Escherichia coli with other Coliforms and Listeria monocytogenes. ${ }^{10}$ In 1879, Louis Pasteur identified the Streptococcus as the causative organism for Puerperal sepsis. Since the early 1930s, when Rebecca Lancefield reported her grouping system for Haemolytic Streptococci, Group A Streptococcus was widely acknowledged as the major pathogen associated with Puerperal sepsis. Group B Streptococcus (GBS) was initially thought to be a commensal until 1937, while Shet et al in India reported 7 cases of GBS associated Puerperal fever with 3 deaths. ${ }^{11}$ Staphylococci or faecal Aerobic Gram negative bacteria (5\%) were isolated from vaginal swabs. ${ }^{12}$

Though Puerperal sepsis is the common cause of maternal morbidity and mortality, it appears to be largely preventable with good antenatal check-up, aseptic delivery practices and postpartum care. When care is delayed or inadequate, infection can progress quickly to generalized sepsis, which can result in infertility, chronic disability and even death. ${ }^{2}$ No study particularly on bacterial aetiology of Puerperal sepsis has been reported. It is known that bacterial pattern with their antimicrobial susceptibility is a dynamic and changing phenomenon and surveillance of this event is needed in every healthcare setting. The study was aimed to determine causative organisms and antibiotic susceptibility of the isolates.

\section{Methods}

This was a cross-sectional study carried out in the Department of Microbiology, Mymensingh Medical College for a period of one year from July, 2006 to June, 2007. Clinically diagnosed 50 patients of Puerperal sepsis admitted in different wards of Obstetrics and Gynecology department of Mymensingh Medical College Hospital were selected for this study.

Cases of Puerperal sepsis were selected on basis of the following clinical findings: fever of $\geq 38.5^{\circ} \mathrm{C}$ within 6 weeks following termination of pregnancy, pelvic pain with offensive and /or purulent vaginal discharge, abdominal pain, and tender uterus, subinvolution of the uterus, and shock. ${ }^{13}$
Patients having two or more of the above features were considered as Puerperal sepsis for the present study. Specimens were collected carefully to avoid normal resident flora. A sterile bi-valve Cusco's vaginal speculum was used to visualize the endocervix under sufficient light. Swab/secretion was taken by gentle rubbing of the mucosa of Cervix or Vagina by sterile cotton swab and secretion was taken by aspiration with a sterile disposable syringe. Cervical swab/secretion was inoculated into Blood agar, MacConkey's agar, Nutrient agar and Mannitol salt agar media and incubated at $37^{\circ} \mathrm{C}$ for 24 hours aerobically. The isolates were identified on the basis of colony morphology, Gram staining and appropriate biochemical tests.

All the Aerobic isolates were subjected to antibiotic susceptibility test by Kirby-Bauer disc diffusion technique following standard procedures. ${ }^{14,15}$ Data regarding age, educational status, parity, personal monthly income, antenatal care, place and mode of delivery, complication during delivery, rupture of membrane, number of vaginal examination, outcome of baby, nature of vaginal discharge and types of Aerobic bacteria from endocervical swabs/ secretions were recorded properly.

\section{Results}

This study included clinically diagnosed 50 cases of Puerperal sepsis. Blood-stained and foul-smelling vaginal discharges were present in 42 (84\%) women, 07 (14\%) had purulent and odorous discharge and only $2 \%$ has non-odorous watery discharge. (Table I)

Table I: Nature of vaginal discharge among the study subjects

\begin{tabular}{lll}
\hline Type of Discharge & No. of case & Percentage (\%) \\
\hline Blood-stained and odorous & 42 & 84.0 \\
Purulent and odorous & 07 & 14.0 \\
Watery, non-odorous & 1 & 2.0 \\
Total & 50 & 100.0 \\
\hline
\end{tabular}

Regarding the results of culture, it was found that out of 50 endocervical specimens, $20(40.0 \%)$ yielded growth of Aerobic bacteria, 22 (44.0\%) yielded mixed growth, i.e. both 
Aerobic and Anaerobic and $08(16.0 \%)$ yielded no growth in culture. (Table II)

Distribution of different Aerobic bacterial isolates were observed and found that Staphylococcus aureus was at the top of the list (26, 61.90\%). Isolation rate of Escherichia coli, S. epidermidis, Streptococcus pyogenes and Enterococcus faecalis were $6(14.28 \%), 5(11.90 \%), 3(7.14 \%)$ and 2 (4.76\%) respectively. (Table III)

Table II: Pattern of culture growth in 50 endocervical specimens

\begin{tabular}{lll}
\hline Pattern of growth & No & Percentage (\%) \\
\hline $\begin{array}{l}\text { Only Aerobic growth, no } \\
\text { growth in Anaerobic culture }\end{array}$ & 20 & 40.0 \\
$\begin{array}{l}\text { Growth in both Aerobic and } \\
\text { Anaerobic culture }\end{array}$ & 22 & 44.0 \\
No growth & 8 & 16.0 \\
\hline
\end{tabular}

Table III: Distribution of Aerobic bacteria from Endocervical specimens $(n=42)$

\begin{tabular}{llcl}
\hline Bacteria & \multicolumn{3}{c}{ No. of bacterial isolates } \\
& $\begin{array}{l}\text { Purely } \\
\text { Aerobic }\end{array}$ & $\begin{array}{c}\text { Aerobic from } \\
\text { mixed growth }\end{array}$ & Total (\%) \\
\hline Staphylococcus aureus & 14 & 12 & $26(61.90 \%)$ \\
Escherichia coli & 2 & 4 & $6(14.28 \%)$ \\
Staphylococcus epidermidis & 2 & 3 & $5(11.90 \%)$ \\
Streptococcus pyogenes & 2 & 1 & $3(7.14 \%)$ \\
Enteroccus faecalis & 0 & 2 & $2(4.76 \%)$ \\
Total & 20 & 22 & $42(100 \%)$ \\
\hline
\end{tabular}

Percentage of antibiotic sensitivity (S) of different Aerobic bacteria shows that all $(26,100 \%)$ of the isolates of Staphylococcus aureus and 5 isolates of $S$. epidermidis were sensitive to Cephalexin, Cephradine, Cefuroxime and Vancomycin. Corresponding values of $S$. aureus and $S$. epidermidis to Amoxicillin, Oxacillin, Ciprofloxacin and Rifampicin were recorded as $30.77 \%$ and $40 \%, 53.85 \%$ and $40 \%, 84.61 \%$ and $100 \%, 92.31 \%$ and $100 \%$, respectively. All isolates $(3,100 \%)$ of Streptococcus pyogenes were sensitive to Amoxicillin, Cephalexin, Cephradine, Cefuroxime and
Ciprofloxacin. Number of isolates of Enterococcus species was 2 and all of them (100\%) were sensitive to Amoxicillin, Oxacillin, Cephalexin, Cephradine and Gentamicin. All (6, $100 \%$ ) of the isolates of Escherichia coli were sensitive to Cephalexin, Cephradine, Cefuroxime, Gentamicin, Amikacin and Ciprofloxacin. (Table IV)

Table IV: Rate of antibiotic sensitivity (S) of different aerobically isolated bacteria

\begin{tabular}{llllll}
\hline Antibiotic & \multicolumn{5}{c}{ Rate (\%) of sensitivity of- } \\
& S. aureus & S. epidermidis & S. pyogenes & Enterococcus spp. & E. coli \\
\hline Amoxicillin & 30.77 & 40 & 100 & 100 & 66.66 \\
Oxacillin & 53.85 & 40 & 100 & 100 & 33.33 \\
Cephalexin & 100 & 100 & 100 & 100 & 100 \\
Cephradine & 100 & 100 & 100 & 100 & 100 \\
Cefuroxime & 100 & 100 & 100 & 100 & 100 \\
Gentamicin & N/D & N/D & N/D & 100 & 100 \\
Amikacin & 84.61 & 100 & N/D & 100 & 100 \\
Ciprofloxacin & 84.61 & 100 & 100 & 50 & 100 \\
Rifampicin & 92.31 & 100 & N/D & N/D & N/D \\
Vancomycin & 100 & 100 & N/D & 100 & N/D \\
\hline & & & & & N/D= Not done
\end{tabular}

\section{Discussion}

Puerperal sepsis is an important cause of hospitalization due to its clinical morbidity. Usually the infection is of polymicrobial in origin with a mixture of both Aerobic and Anaerobic organisms. ${ }^{16}$ The present study was conducted to see the above parameters in one of the largest tertiary hospitals in Bangladesh where a large number of patients particularly from lower socio-economic condition seek admission for proper management.

An observation by Gibbs (1980) found 58 cases of Endometritis as a complication of vaginal delivery. ${ }^{17}$ In another observation conducted in Bangladesh, it was noted that occurrence of foul smelling vaginal discharge remained high ( $31 \%$ up to 2 weeks and $7.1 \%$ up to 6 weeks of delivery) in women whose delivery was conducted by untrained personnel at home. ${ }^{18}$ Persistent vaginal discharge might be due to prevailing infection either in mild or in severe form. The infectious agents of course are being transmitted from the hands of non-trained personnel including Dais, neighbours or in-laws. Certain practices such as not cleaning the birth canal with water and antiseptic, frequent digital examination with unwashed hands and intra-vaginal application of ghee or other herbal products by untrained health personnel were 
found to enhance the risk of vaginal infections. ${ }^{19}$ In the present study, out of 50 endocervical specimens, Aerobic and mixed growth (both Aerobic and Anaerobic) was observed in $40 \%$ and $44 \%$ samples respectively. This finding was compared with a study conducted with transcervical endometrial swabs from 51 women showing Aerobic bacteria from $85.2 \%$ cases following vaginal delivery and $75.1 \%$ following Caesarean Section, which is not consistent with findings $(40 \%)$ of the present study. The study also yielded mixed growth (Aerobic and Anaerobic) in 48.1\% cases that showed very good correlation (44\%) with that of the current study. Because administering prophylactic antibiotic injection or capsule following delivery is almost routinely practiced by rural practitioners or even in hospitals and as this was not perfectly ruled out, this practice may contribute to the lower isolation rate of the Aerobic organisms.

Distribution of Aerobic bacteria as the cause of Puerperal sepsis observed in the present study was in agreement with a study by Chaisil Watana (1991) that showed predominance of (78\%) of Gram positive cocci with $8 \%$ isolates being Gram negative bacteria. ${ }^{20}$ Another study done in UK on 286 women with vaginal swabs found heavy growth of $S$. aureus, Beta Haemolytic Streptococcus (Gr A, C or G), S. pneumoniae or Haemophilus influenzae. ${ }^{21}$ Pokharel (2004) reported S. aureus as the commonest $(50 \%)$ organism causing postpartum genital infections in women who delivered their babies with premature rupture of membrane, whereas women who delivered their babies with rupture of membrane in due time developed postpartum genital infections by E. coli $(28.8 \%){ }^{22}$

Other studies done in abroad or in home observed variations in the distribution of Aerobic bacteria causing Puerperal sepsis. In this context, one study done in Sir Salimullah Medical College and Mitford Hospital found E. coli as the predominant bacteria (50\%) followed by Staphylococcus species (30\%) and Streptococcus species (20\%). ${ }^{23}$ Distribution of E. coli, Staphylococcus species and Streptococcus species in another study done in USA was reported to be $36 \%, 28 \%$ and $21 \%$ respectively. ${ }^{24}$ Another study done in Pakistan (Mayo hospital, Lahore) reported isolation rate of Gram positive cocci as $40 \%$ and Gram negative bacilli as $60 \%$ from cases of Puerperal sepsis. ${ }^{25}$ The most common Gram positive bacteria found in the study were $S$. aureus, $S$. epidermidis and Enterococcus. The most common Gram-negative bacteria were E. coli, Klebsiella pneumoniae and Pseudomonas aeruginosa. Anaerobes were equally important. ${ }^{25}$ Other studies from India reported E. coli as the most common organism isolated from maternal genital tract followed by $S$. aureus and K. pneumoniae. ${ }^{26,27}$ In western country, Group B Streptococcus was found to be the most common organism implicated in maternal genital tract colonization resulting Puerperal infection of mother and also to babies. ${ }^{28}$ Another study observed that in cases of Puerperal sepsis the most common bacteria were S. epidermidis, E. coli, Enterococci and Streptococci. ${ }^{29}$

The variation of bacteria isolated from genital tract causing Puerperal infection as endogenous source may represent regional variation of genital flora. ${ }^{27}$ In addition, the source of infection might be exogenous where pathogens from nearby skin flora or from contact with contaminated instruments, dressings or pads are implanted in the mucosa of genital tract.

In the present study, antimicrobial susceptibility of different Aerobic bacterial isolates was seen. All the strains of $S$. aureus and $S$. epidermidis were sensitive to Cephalexin and Vancomycin. Similarly all the strains of $E$. coli were sensitive to Gentamicin, Amikacin, Ciprofloxacin and Cephalexin. All the strains of $S$. pyogenes were sensitive to Amoxicillin also. All five isolates of $S$. epidermidis (100\%) and majority $(84.6 \%)$ of the $S$. aureus strains were sensitive to Ciprofloxacin. All the isolates of Enterococus were sensitive to Amoxicillin and Cephalexin. Kankuriesko and others (2003) reported that majority of different Aerobic bacteria $(81 \%)$ isolated from cases of Puerperal sepsis were sensitive against first and second generation Cephalosporins. ${ }^{30}$ Another study from Nepal also observed that $100 \%$ strains of different Aerobic bacteria were sensitive to Cephalexin. ${ }^{22}$ Findings of the two studies mentioned above were well consistent with results of the present study. E. coli and other Gram negative bacteria showed $100 \%$ sensitivity towards Gentamicin in a study by Modi et al (1986) in India that also stood highly comparable to the results of the present study. ${ }^{31}$ Isolates of the genus Staphylococcus in the present study were $100 \%$ susceptible to Vancomycin that was in close accordance with a report from the USA. ${ }^{32}$

Sensitivity to Ciprofloxacin (Quinolone) among different Aerobic bacteria as found in the present study, well compared with that of the Martens et al (1991) investigating 231 patients of postpartum Endometritis. ${ }^{33}$ In this regard, sensitivity towards second generation Cephalosporins was also consistent with present study results. Isolates of 
Enterococcus of the mentioned study also showed $>85 \%$ strains susceptible to Ampicillin and Gentamicin. In the current study, only 02 strains were identified as E. faecalis and were tested against Amoxicillin instead of Ampicillin and found sensitive. The strains were also sensitive to Ciprofloxacin and Gentamicin.

Another study reporting antimicrobial susceptibility of 55 strains of E. faecalis from lower genital tract showed that sensitivity towards Carbenicillin, Azlocillin and Ampicillin were $92.7 \%, 91.2 \%$ and $83.9 \%$ respectively. The values for resistance of the organism towards Gentamicin and Amikacin were $49.5 \%$ and $46.5 \%$ respectively. ${ }^{34}$

Whatever might be the pattern of susceptibility obtained in the present study, property of antibiotic resistance among bacterial population is not a static phenomenon. It is related with magnitude of clinical use, proper dose, adequate duration and close monitoring of bacterial eradication from the site of infection. Despite all the factors having at substandard level in Bangladesh, the susceptibility pattern of Aerobic bacterial strains of the present study is not alarming. On analyzing the findings of the present study, it can be concluded that Puerperal sepsis is the common lifethreatening condition in the postnatal period, particularly following vaginal delivery at home. The multiparous, illiterate women from low socio-economic class obtaining no antenatal checkup, bear significant risks for developing Puerperal sepsis.

\section{References}

1. Dolea C, Stein C. Global burden of maternal sepsis in the year 2000. Geneva: World Health Organization; 2003.

2. Dare FO, Bako AU, Ezechi OC. Puerperal sepsis: a preventable postpartum complication. Tropical Doctor 1998; 28: 92-95

3. Prual A, Hugnet D, Garbin O, et al. Severe Obstetric morbidity of the third trimester, delivery and early Puerperium in Niamey (Niger). Revue Africaine de la Sante Reproductive 1998; 2(1): 10-19.

4. Mantel GD, Buchamann E, Rees H, Pattinson RC. Severe acute maternal morbidity: a pilot study of a definition for a near-miss. Br J Obstet Gynaecon 1998; 105(9): 985-990.

5. Brentlinger PE, Capps L. Pregnancy outcomes in EI Salvador during the post war period. Int J Gynecol Obstet 1998; 61: 5962.

6. Jolly M, Sebire M, Harris J, Robinso S, Regan L. The risk associated with Pregnancy in women aged 35 years or older. Hum Reprod 2000; 15 (11): 2433-2437.

7. Begum N. Maternal mortality in Mymensingh Medical College Hospital: 1984-88. Bangladesh J Obstet Gynecol 1991; 6(1): 14-21.

8. Bhuiyan AS, Rahman JMMA, Salahuddin KMA. A study on causes of maternal mortality in a teaching hospital in Bangladesh. Dhaka Shishu Hosp J 1986; 2(3): 88.

9. Maureen C. The global incidence of Puerperal sepsis. Geneva: Foundation for Medical Education and Research; 2004.

10. Cheesbrough M. Microbiological tests: Examination of urogenital specimens. In: District Laboratory Practice in Tropical Countries, Part 2. United Kingdom: Cambridge University Press; 2000: p. 90.

11. Shet A, Ferrieri P. Neonatal \& maternal Group B Streptococcal infections: A comprehensive review. Indian J Med Res 2004; 120: $141-150$.

12. Percival R, ed. The Puerperium. In: Holland and Brews Manual of Obstetrics, 14th ed. United States of America: Churchill Livingstone; 1980: pp. 570-613.

13. Basu SK. Rural Surgeons and Obstetrical emergencies. Indian J Surg 2003; 65: 77-85.

14. Bauer AW, Kirby WMM, Sherris JC, Turck M. Antibiotic susceptibility testing by a standardized single disk method. Am J Clin Pathol 1966; 45: 493-501.

15. National Committee for Clinical Laboratory Standards. Performance standards for antimicrobial disk susceptibility tests. Tentative standard M2-A6. Villanova, Pa.: NCCLS; 1997.

16. Stevens DL. Infections due to Gram-Positive cocci: Streptococci. Infectious disease. ACP Medicine Online. Webpage retrieved from: "http://www.medscape.com" [accessed on: O6/07/2006]

17. Gibbs RS, Rodgers PJ, Castaneda YS, Ramzy I. Endometritis following vaginal delivery. Obstet Gynecol 1980; 56 (5): 555558.

18. Goodburn EA, Chowdhury M, Gazi R, Marshall T, Graham W. Training traditional birth attendants in clean delivery does not prevent postpartum infection. Health Policy Plan 2000; 15 (4): 394-399.

19. Ali TS, Fikree FF, Rahbar MH, Mahmud S. Frequency and determinants of vaginal infection in postpartum period: a cross- 
sectional survey from low socioeconomic settlements, Karachi, Pakistan. J Pakistan Med Assoc 2006; 56 (3): 95-98.

20. Chaisilwatana P, Roongpisuthipong A. Causative organism in Puerperal infection. J Med Assoc Th 1991; 74(3): 159-161.

21. Dykhuizen RS, Harvey G, Gould IM. The high vaginal swab in general practice: Clinical correlates of possible pathogens. Family Practice 1995; 12 (2): 155-158.

22. Pokharel MS. Study on antibiotics sensitivity pattern of bacterial flora in cases of pre-labour rupture of membrane. [Dissertation] Kathmandu, Nepal: Tribhuvan University; 2004: p. 108.

23. Baker JN. Study of cases of Puerperal pyrexia in a tertiary level hospital. [Dissertation] Dhaka, Bangladesh: Sir Salimullah Medical College and Mitford hospital; 2005: p. 34.

24. Decherny AH, Nathan L. Postpartum hemorrhage and the abnormal puerperium In: Current Obstetrics and Gynecologic diagnosis and treatment, 9th ed. UK: Prentice Hall International Inc.; 2003: pp. 531-552.

25. Naheed T, Akber N, Akber N. Patients with postpartum complications admitted in a Medical ward of Mayo Hospital, Lahore, Pakistan. J Med Sc 2002; 18 (2): 126-130.

26. Roa K, Ramji S, Thirupuram S, Prakash K. Clinical and bacteriological study of normal and inflamed neonatal conjunctiva. Indian Pediatr 1992; 29: 161-165.

27. Kerur BM, Bhatt BV, Harish BN, Habeebullah S, Kumar CU.
Maternal genital bacteria and surface colonization in early neonatal sepsis. Indian J Pediatr 2006; 73 (1): 29-32.

28. Beagie R, Priscilla L, Elon T, John D. Perinatal infection and vaginal flora. Am J Obstet Gynecol 1975; 122: 31-33.

29. Gerstner G, Leodolter S, Rotter M. Endometrial bacteriology in Puerperal infections. Z Geburtshilfe Perinatol 1981; 185 (5): 276-279.

30. Kankuriesko E, Kurkitatio T, Carison T, Esmaa HM. Incidence, treatment and outcome of peripartum sepsis. Acta Obstet Gynecol Scan 2003; 82 (8); 730-735.

31. Modi S, Kar J, Gupta U. Puerperal sepsis. Cur Med Pract 1986; 30 (12): 301-306.

32. Rotas M, McCalla S, Liu C, Minkoff H. Methicillin resistant Staphylococcus aureus necrotizing pneumonia arising from an infected episiotomy site. Obstet Gynecol 2007; 109 (2): 533536.

33. Martens MG, Faro S, Maccato M, Riddle G, Hammill HA. Susceptibility of female pelvic pathogens to oral antibiotic agents in patients who develop postpartum Endometritis. Am J Obstet Gynecol 1991; 164:1383-1386.

34. Shopova E. The sensitivity to antibacterial preparations of Enterococcus strains isolated from Gynecological patients, Pregnant women, Guerperal and newborn infants. Akush Ginekol (Sofiia)1995; 34(3): 32-34. 